\title{
The Cross Talk Between p53 and mTOR Pathways in Response to Physiological and Genotoxic Stresses
}

\author{
Danrui Cui ${ }^{1,2,3}$, Ruirui $Q u^{1,2,4}$, Dian Liu ${ }^{1,2,4}$, Xiufang Xiong ${ }^{4,5}$, Tingbo Liang $^{1,2,3}$ and \\ Yongchao Zhao ${ }^{1,2,3,4 *}$
}

${ }^{1}$ Department of Hepatobiliary and Pancreatic Surgery, The First Affiliated Hospital, Zhejiang University School of Medicine, Hangzhou, China, ${ }^{2}$ Zhejiang Provincial Key Laboratory of Pancreatic Disease, The First Affiliated Hospital, Zhejiang University School of Medicine, Hangzhou, China, ${ }^{3}$ Cancer Center, Zhejiang University, Hangzhou, China, ${ }^{4}$ Institute of Translational Medicine, Zhejiang University School of Medicine, Hangzhou, China, ${ }^{5}$ Cancer Institute of the Second Affiliated Hospital, Zhejiang University School of Medicine, Hangzhou, China

OPEN ACCESS

Edited by:

Xiang Zhou,

Fudan University, China

Reviewed by:

Hongbing Liu,

Tulane University, United States

Fabio Luis Forti,

University of São Paulo, Brazil

${ }^{*}$ Correspondence:

Yongchao Zhao

yongchao@zju.edu.cn

Specialty section:

This article was submitted to Molecular and Cellular Oncology,

a section of the journal

Frontiers in Cell and Developmental

Biology

Received: 14 September 2021 Accepted: 03 November 2021

Published: 18 November 2021

Citation:

Cui D, Qu R, Liu D, Xiong X, Liang T

and Zhao Y (2021) The Cross Talk

Between p53 and mTOR Pathways in

Response to Physiological and

Genotoxic Stresses.

Front. Cell Dev. Biol. 9:775507.

doi: $10.3389 /$ fcell.2021.775507
The tumor suppressor p53 is activated upon multiple cellular stresses, including DNA damage, oncogene activation, ribosomal stress, and hypoxia, to induce cell cycle arrest, apoptosis, and senescence. Mammalian target of rapamycin (mTOR), an evolutionarily conserved serine/threonine protein kinase, serves as a central regulator of cell growth, proliferation, and survival by coordinating nutrients, energy, growth factors, and oxygen levels. p53 dysfunction and mTOR pathway hyperactivation are hallmarks of human cancer. The balance between response to stresses or commitment to cell proliferation and survival is governed by various regulatory loops between the p53 and mTOR pathways. In this review, we first briefly introduce the tumor suppressor p53 and then describe the upstream regulators and downstream effectors of the mTOR pathway. Next, we discuss the role of p53 in regulating the mTOR pathway through its transcriptional and non-transcriptional effects. We further describe the complicated role of the mTOR pathway in modulating p53 activity. Finally, we discuss the current knowledge and future perspectives on the coordinated regulation of the p53 and mTOR pathways.

Keywords: p53, mTOR, transcription, miRNA, tumorigenesis, MDM2, post-translation

\section{INTRODUCTION: THE TUMOR SUPPRESSOR P53}

p53, a well-known tumor suppressor, acts as a "guardian of the genome" to maintain genome stability and cellular homeostasis (Vousden and Prives, 2009; Hafner et al., 2019). Upon induction of various cellular stresses, especially DNA damage, p53 is activated to induce cell cycle arrest, apoptosis, and senescence which suppress tumorigenesis by eliminating damaged and potentially precancerous cells. p53 is the most frequently mutated gene in human cancers (Hainaut and Hollstein, 2000). Approximately $50 \%$ of human tumors carry p53 mutations, and in over $80 \%$ of the tumors the p53 pathway is dysfunctional (Ozaki and Nakagawara, 2011). As a transcription factor, p53 exerts tumor-suppressive effects by directly binding to specific DNA sequences to activate or repress the transcription of target genes, such as MDM2 (Barak et al., 1993), p21 (elDeiry et al., 1993), NOXA (Oda et al., 2000), PUMA (Nakano and Vousden, 2001), and RPS27L (He and Sun, 2007; Li et al., 2007) [for review, see (Fischer, 2017)]. The canonical p53 binding sequence RRRC (A/T) (A/T)GYYY $(\mathrm{N})_{0-13}$ RRRC (A/T) (A/T)GYYY (R: A or G, Y: C or T, and N: any nucleotide) is normally located near the transcription start site (Hafner et al., 2019). 


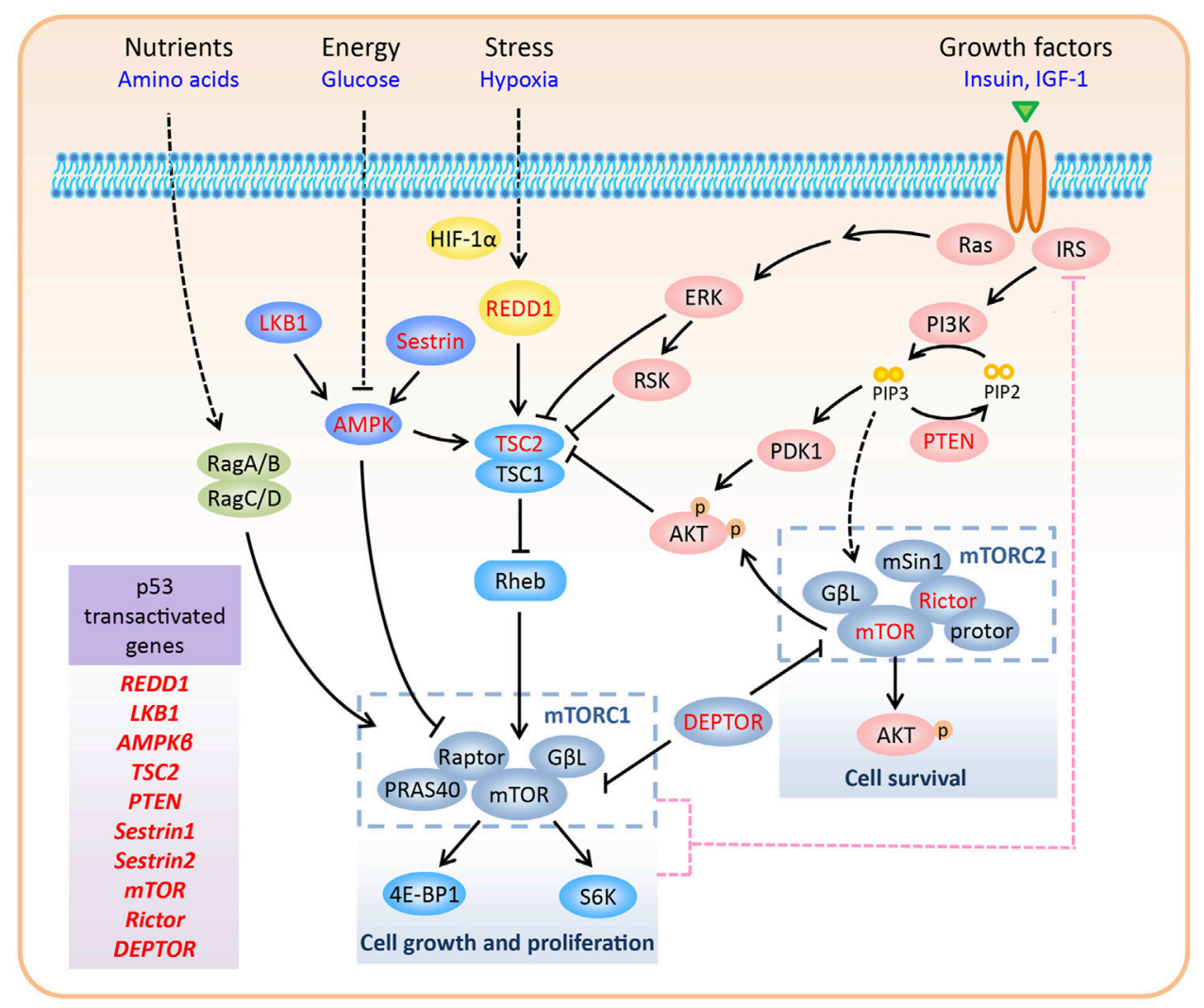

FIGURE 1 | Regulation of the mTOR pathway. In mammalian cells, mTOR forms two complexes with distinctive structure and functions, namely mTORC1 and mTORC2. mTORC1 promotes cell growth and proliferation via phosphorylation of S6K and 4E-BP1. In contrast, mTORC2 regulates cell survival by phosphorylating Ser473 of AKT. mTORC1 responds to various signals, including nutrients, energy, growth factors, and oxygen levels. Upon negative feedback from mTORC1/S6K to IRS1/PI3K signaling, hyper-activated mTORC1 inhibits the activity of mTORC2. Various components of the mTOR pathway are directly transactivated by p53, including REDD1, LKB1, AMPK $\beta$, TSC2, PTEN, Sestrin1/2, mTOR, Rictor, and DEPTOR (highlighted in red color in the figure).

Given the key role of p53 in tumorigenesis, the protein levels and activity of p53 are precisely regulated by multiple regulators [for review, see (Kruse and Gu, 2009; Chao, 2015)], among which the E3 ubiquitin ligase, mouse double minute 2 homolog (MDM2), is the pivotal negative regulator (Hock and Vousden, 2014). Under non-stressed conditions, MDM2 binds specifically to $\mathrm{p} 53$ and promotes the ubiquitination and proteasomal degradation of p53, which maintains p53 at low levels. In response to stress signals, such as DNA damage, certain kinases, such as ATM and $\mathrm{CHK} 2$, are activated to phosphorylate p53 and abolish the interaction between p53 and MDM2, leading to $\mathrm{p} 53$ stabilization and transcriptional activation or repression of downstream target genes. When DNA repair is completed, p53 returns to basal levels, and subsequently, the cell cycle is restored to normal progression. The E3 ligase F-box and WD repeat domain-containing 7 (FBXW7) plays an important role in p53 turnover during DNA damage recovery (Galindo-Moreno et al., 2019; Tripathi et al., 2019; Cui et al., 2020b).

p53 dysfunction and hyperactivation of the mTOR pathway are hallmarks of human cancer (Hanahan and Weinberg, 2011). Accumulating evidence indicates that the tumor suppressor p53 regulates the machinery of the mTOR pathway at multiple levels to control a broad array of cellular processes, including cell proliferation, apoptosis, autophagy, migration, and tumorigenesis. In this review, we summarize the current knowledge regarding the role of p53 in the regulation of the mTOR pathway through transcriptiondependent and transcription-independent mechanisms. A thorough understanding of the interplay between p53 and the mTOR pathway will shed light on the development of novel strategies for cancer therapy.

\section{The mTOR Pathway}

The mammalian target of rapamycin (mTOR), an evolutionarily conserved serine/threonine protein kinase, is a member of the phosphoinositide-3-kinase (PI3K)-related kinase (PIKK) family, along with ATM, ATR, DNA-PK, and SMG-1 (Lovejoy and Cortez, 2009). While all members of the family are involved in DNA damage response, mTOR also responds to various other signals, including nutrients, energy, growth factors, and oxygen levels. By integrating both extracellular and intracellular signals, mTOR coordinates cellular anabolic and catabolic processes, including cell growth, proliferation, survival, and autophagy (Figure 1). 


\section{mTOR and its Effectors}

In mammalian cells, mTOR forms two complexes with distinctive structures and functions, namely mTORC1 and mTORC2. mTORC1 is composed of mTOR, Raptor, PRAS40, and G $\beta \mathrm{L}$, whereas mTORC2 consists of mTOR, Rictor, mSin1, protor, and GßL (Zhao and Sun, 2012; Saxton and Sabatini, 2017). Although the mTOR protein, which is present in both the complexes, was discovered as an interacting protein of the rapamycin-FKBP12 complex, only mTORC1 is sensitive to rapamycin inhibition (Sabatini et al., 1994). Recently, the core structure of mTORC2 has been resolved, and it has been shown that the rapamycinFKBP12 binding domain in mTOR is masked by the C-terminus of Rictor, thus resolving the rapamycin insensitivity of mTORC2 (Scaiola et al., 2020). DEP domain-containing mTOR-interacting protein (DEPTOR) inhibits mTORC1 and mTORC2 by directly binding to mTOR via its PDZ domain (Peterson et al., 2009). mTORC1 has two major substrates, S6K and 4E-BP1, which regulate several aspects of mRNA translation (Sengupta et al., 2010). Thus, mTORC1 promotes cell growth and proliferation by modulating phosphorylation-dependent mRNA translation. However, the effectors of mTORC2 are primarily AGC kinases, including AKT, PKC, and SGK1 (Fu and Hall, 2020). mTORC2 regulates cell survival by phosphorylating Ser473 of $\mathrm{AKT}$, the best-characterized mTORC2 substrate. Compared to mTORC1, much is still unknown about the upstream regulators of mTORC2 (Figure 1). Thus, in the next section, we focus on the regulation of $\mathrm{mTORC1}$ in response to various signals.

\section{Regulation of mTORC1 by Upstream Signals}

Upstream signals regulate mTORC1 activity mainly through two mechanisms: by direct control of mTORC1 components or by the supervision of Rheb GTPase, which interacts with and activates mTORC1 (Long et al., 2005). Tuberous sclerosis complex 2 (TSC2), a GTPase-activating protein (GAP) for Rheb, together with its partner TSC1, inactivates Rheb GTPase (Inoki et al., 2003). Below, we describe the manner in which mTORC1 is either activated or inactivated by distinct upstream signals.

1) Growth factors: Growth factors, such as insulin and insulinlike growth factor 1 (IGF-1), promote cellular anabolic processes by activating mTORC1. The binding of insulin/IGF-1 to its receptor recruits insulin substrate 1 (IRS1) to the receptor and activates PI3K, which phosphorylates PIP2 to PIP3. PIP3 recruits AKT to the plasma membrane, where it is fully activated by direct phosphorylation of Thr308 by PDK1 and Ser473 by mTORC2. During growth factor signaling, AKT (Inoki et al., 2002; Manning et al., 2002; Potter et al., 2002), along with other kinases such as ERK and RSK (Roux et al., 2004; Ma et al., 2005), phosphorylates and inhibits TSC2, leading to the activation of Rheb and mTORC1. Growth factor-activated AKT also stimulates mTORC1, independent of TSC2. AKT can directly phosphorylate prolinerich AKT substrate of $40 \mathrm{kDa}$ (PRAS40), a negative regulator of mTORC1, that inhibits the interaction between mTORC1 and its substrates, and dissociates itself from mTORC1 (Sancak et al., 2007; Haar et al., 2007).

2) Glucose and energy: Glucose deprivation decreases glycolytic flux and inhibits mTORC1 by lowering ATP levels.
LKB1 and AMPK are two major upstream kinases of the mTOR pathway and are involved in monitoring the levels of glucose and energy (ATP and AMP) (Inoki et al., 2003; Shaw et al., 2004; Gwinn et al., 2008). In response to increased AMP/ATP ratio, LKB1 phosphorylates AMPKa (the catalytic subunit of AMPK) on Thr172 to activate AMPK. Activated AMPK phosphorylates TSC2 (Inoki et al., 2003) and Raptor (Gwinn et al., 2008) to inhibit mTORC1.

3) Hypoxia: Under hypoxic conditions, HIF-1a promotes the expression of REDD1 to inhibit mTORC1 by activating the TSC1TSC2 complex (Brugarolas et al., 2004). Mechanistically, REDD1 may release TSC2 from its inhibitory protein 14-3-3, thus facilitating the interaction between TSC1 and TSC2 (DeYoung et al., 2008; Vega-Rubin-de-Celis et al., 2010). In addition to hypoxia, REDD1 is induced by several cellular stressors, including reactive oxygen species (ROS), glucocorticoids, DNA damage, and heat shock (Ellisen et al., 2002; Wang et al., 2003), indicating a universal function of REDD1 in coordinating stress signals to mTORC1.

4) Amino acid: Amino acid signaling recruits and activates mTORC1 to the lysosomal membrane, where a pool of Rheb resides. In this process, the Rag GTPase heterodimer (consisting of RagA/B and RagC/D), which is activated by amino acids, serves as a scaffold for mTORC1 via interacting with Raptor (Sancak et al., 2008; Sancak et al., 2010).

\section{Feedback Loop Between mTORC1 and mTORC2}

As a negative regulator of IRS1, mTORC1 also acts upstream of the PI3K-AKT pathway to inhibit mTORC2. This negative feedback loop is initiated through multiple mechanisms. First, S6K, a substrate of mTORC1, decreases the activity and protein levels of IRS1 by phosphorylating it (Harrington et al., 2004; Um et al., 2004; Shah et al., 2004). Second, mTORC1 phosphorylates and stabilizes growth factor receptor-bound protein 10 (Grb10), which inhibits IRS1/2 phosphorylation and destabilizes IRS1 (Hsu et al., 2011; Yu et al., 2011). Third, mTORC1 directly phosphorylates IRS1 at sites that inhibit its interaction with PI3K (Tzatsos, 2009). Therefore, high levels of DEPTOR, a natural inhibitor of both mTORC1 and mTORC2, inhibit mTORC1 and activate mTORC2 by relieving the feedback inhibition from mTORC1 to IRS1/PI3K signaling (Peterson et al., 2009; Zhao et al., 2011; Zhao and Sun, 2012; Cui et al., 2020a) (Figure 1).

\section{Regulation of the mTOR Pathway by p53}

To maintain normal cell growth and proliferation, it is important for cells to coordinate stimulatory signals (such as nutrients, energy, and growth factors) and inhibitory stresses (such as DNA damage and hypoxia). The tumor suppressor p53, a stressinduced transcription factor, can inhibit cell growth and proliferation via its target genes, such as the cyclin-dependent kinase (CDK) inhibitor p21, which serves as a cell cycle inhibitor (Levine, 1997). More recently, elucidating the mechanism of p53 in directly regulating the mTOR pathway has become an attractive area of research due to the critical roles of p53 and mTOR in tumorigenesis. In the following sections, we discuss the emerging roles of $\mathrm{p} 53$ in controlling the mTOR pathway through its transcriptional and non-transcriptional effects. 
TABLE 1 | Target genes of p53 involved in mTOR signaling.

\begin{tabular}{|c|c|c|c|}
\hline Targets & Position & Sequence & Refs \\
\hline REDD1 & $-601 \sim-582$ & AAACAAGTCTाTCCTTGATC & Ellisen et al. (2002) \\
\hline LKB1 & $-108 \sim-88$ & AACCAACGGGTGGGCACGTCG & Co et al. (2014); Xie et al. (2017) \\
\hline AMPK $\beta$ & Exon 1 & GTTCTTGCCGCGGCTTGCCT & Feng et al. (2007) \\
\hline \multirow[t]{3}{*}{ TSC2 } & Intron $2 \mathrm{a}$ & AGGCTAGTCTGAAACTCCTGGGCTGACGTGAC & Feng et al. (2007) \\
\hline & Intron $2 \mathrm{~b}$ & GGGCATGGTGGCACATGCCT & \\
\hline & Intron 11 & TAACAAGCTCGGGGCTAGCCC & \\
\hline PTEN & $-1190 \sim-1157$ & GAGCAAGCCCCAGGCAGCTACACTGGGCATGCTC & Stambolic et al. (2001) \\
\hline Sestrin1 (PA26) & $-1241 \sim-1222$ & GGACAAGTCTCCACAAGTCA & Velasco-Miguel et al. (1999) \\
\hline Sestrin2 (Hi95) & Not identified & Not identified & Budanov et al. (2002) \\
\hline mTOR & $0.5 \mathrm{~kb}$ upstream promoter & Not identified & Ge et al. (2019) \\
\hline Rictor & $0.5 \mathrm{~kb}$ upstream promoter & Not identified & Ge et al. (2019) \\
\hline DEPTOR & $-196 \sim-169$ & GCTCAAGTTCTGGGGCCGGACTAGCCC & Cui et al. (2020a) \\
\hline
\end{tabular}

\section{Target Genes of p53 in the mTOR Pathway}

Upon multiple stresses, p53 is activated to inhibit cell growth and proliferation, which undergo high error rates upon induction of stress. Thus, inhibition of mTORC1, which promotes cell growth and proliferation, is an important hallmark of the cellular stress response. Actually, multiple negative regulators of $\mathrm{mTORC1}$, as discussed earlier, are direct transcriptional targets of p53, including REDD1 (Ellisen et al., 2002), LKB1 (Co et al., 2014; Xie et al., 2017), $A M P K \beta$ (a regulatory subunit of AMPK) (Feng et al., 2007), and TSC2 (Feng et al., 2007). Moreover, PTEN, which encodes a phosphatase that catalyzes PIP3 to PIP2 to inactivate the PI3KAKT pathway, contains p53 binding sites and is transactivated by p53 (Stambolic et al., 2001). Finally, upon genotoxic stress, p53 also promotes the transcription of Sestrin1 and Sestrin2 to inhibit mTORC1, through activation of AMPK and TSC2 (Budanov and Karin, 2008) (Figure $\mathbf{1}$ and Table 1).

Contrary to the inhibitory effect of p53 target genes in controlling mTORC1, the function of these genes in mTORC2 seems much more complex, being highly cell- and contextdependent. In the alternative lengthening of telomeres (ALT) cancer cells (such as U2OS cells), p53 stimulates the transcription of mTOR and Rictor, two important components of mTORC2, to activate AKT and inhibit apoptosis (Ge et al., 2019). Recently, our group reported that DEPTOR is a direct target of p53 and its expression is positively correlated with p53 activity, both in cultured cancer cells and mouse tissues under normal conditions, and is further induced by activated p53 under genotoxic conditions. Given that DEPTOR inhibits both mTORC1 and mTORC2, and there is a negative feedback from mTORC1 to IRS1/PI3K signaling, p53-mediated DEPTOR expression has distinct roles in regulating mTORC2 under non-stressed and genotoxic stress conditions. In nonstressed cells, p53-mediated DEPTOR expression inhibits mTORC2 activity, which is reflected by the decreased phosphorylation of AKT at Ser473; whereas, upon genotoxic treatment, the dramatic induction of DEPTOR expression via p53 hyperactivation inhibits mTORC1, subsequently alleviating the feedback inhibition from mTORC1 to IRS1, thereby activating mTORC2 via IRS1/PI3K signaling (Cui et al., 2020a) (Figure 1 and Table 1).

\section{p53 Regulates the mTOR Pathway via microRNAs}

The discovery of microRNAs (miRNA or miR) has added another layer of complexity to the regulation of the mTOR pathway by p53. miRNAs are a class of endogenously expressed small non-coding RNAs (17-24 nucleotides) that regulate the expression of multiple genes at the post-transcriptional level (Macfarlane and Murphy, 2010). miRNAs inhibit protein expression by enhancing mRNA degradation or suppressing translation via partial base pairing with the $3^{\prime}$-untranslated region ( $3^{\prime}$-UTR) of the target mRNA of protein coding genes (Lewis et al., 2005). miRNAs play critical roles in several biological processes, including proliferation, survival, metastasis, and stemness. In particular, overexpression of oncogenic miRNAs or downregulation of tumor-suppressive miRNAs contributes to tumorigenesis (Babashah and Soleimani, 2011). It is well established that p53 is an important regulator of miRNAs (Hermeking, 2007). Global sequence analysis showed that more than $46 \%$ of the 326 miRNA promoters contain putative p53 binding sites in HCT116 cells (Xi et al., 2006). In addition, various miRNAs have been identified as direct transcriptional targets of p53 and many of them are involved in p53-mediated tumor-suppressive functions (Hermeking, 2012). Moreover, besides the regulation of miRNAs at the transcriptional level, p53 promotes the maturation of certain miRNAs at the post-transcriptional level (Suzuki et al., 2009). Conversely, many miRNAs directly downregulate $\mathrm{p} 53$ protein levels by binding to the $3^{\prime}$-UTR of p53 mRNA (Liu et al., 2017).

Accumulating evidence shows that a large number of miRNAs act opposingly on the mTOR pathway, which is often hyperactivated in cancers (Zhang et al., 2017). Thus, p53 exerts its control on the mTOR pathway via miRNAs. Among all miRNAs, members of the miRNA-34 family (miR-34a/b/c) have been identified as the most common targets of p53 with the highest induction by activated p53 (Hermeking, 2007). Overexpression of miR-34a in prostate cancer cells inhibited the phosphorylation of AMPK and upregulated the phosphorylation of mTOR. As a result, miR-34a sensitizes cancer cells to chemotherapy by inhibiting autophagy through the AMPK-mTOR axis (Liao et al., 2016). However, the direct 
TABLE 2 | p53 regulates the mTOR pathway via microRNAs.

\begin{tabular}{|c|c|c|c|c|c|}
\hline miRNAs & $\begin{array}{c}\text { p53-mediated } \\
\text { regulation } \\
\text { of miRNA }\end{array}$ & $\begin{array}{c}\text { The effects } \\
\text { of p53 } \\
\text { on miRNA } \\
\text { expression }\end{array}$ & $\begin{array}{c}\text { miRNA targets } \\
\text { in mTOR } \\
\text { signaling }\end{array}$ & $\begin{array}{l}\text { The effects } \\
\text { on mTOR } \\
\text { signaling }\end{array}$ & Refs \\
\hline miR-34 & Transcriptional & Upregulation & Unknown & Activation & Hermeking. (2007); Liao et al. (2016) \\
\hline $\mathrm{miR}-100$ & Transcriptional & Downregulation & mTOR & Suppression & $\begin{array}{l}\text { Sun et al. (2013); Xu et al. (2013); Zhang et al. (2014a); Ghose and } \\
\text { Bhattacharyya (2015) }\end{array}$ \\
\hline miR-101 & Post-transcriptional & Upregulation & mTOR & Suppression & Lin et al. (2014); Fujiwara et al. (2018) \\
\hline miR-145 & Transcriptional & Upregulation & S6K1 & Suppression & Sachdeva et al. (2009); Xu et al. (2012) \\
\hline miR-149 & Transcriptional & Upregulation & AKT1 & Suppression & Jin et al. (2011); Zhang et al. (2014b) \\
\hline miR-155 & Transcriptional & Upregulation & $\begin{array}{l}\text { Rheb, Rictor, and } \\
\text { S6K2 }\end{array}$ & Suppression & Wang et al. (2013); Wan et al. (2014); Wang et al. (2018) \\
\hline $\begin{array}{l}\operatorname{miR}- \\
199 a-3 p\end{array}$ & Post-transcriptional & Upregulation & mTOR & Suppression & Fornari et al. (2010); Wang et al. (2012a); Wu et al. (2013) \\
\hline
\end{tabular}

target(s) of miR-34 in regulating the mTOR pathway remains to be elucidated. Currently, some other miRNAs, directly regulated by $\mathrm{p} 53$, are emerging as vital regulators of the mTOR pathway at the post-transcriptional level, and these miRNAs, downstream of p53, are as follows (Table 2):

1) miR-100: miR100, a member of the miR-99 family (including miR-99a, miR-99b, and miR-100), is negatively regulated by $\mathrm{p} 53$. p53 binds to the upstream sequences of miR-100 and suppresses its transcription in both mouse striatal cells and human cervical carcinoma HeLa cells (Ghose and Bhattacharyya, 2015). miR-100 inhibits the expression of mTOR by directly targeting its $3^{\prime}$-UTR and acts as a tumor suppressor in esophageal squamous cell carcinoma (ESCC) (Sun et al., 2013; Zhang N. et al., 2014) and bladder cancer (Xu et al., 2013). Thus, p53 may activate the mTOR pathway by inhibiting the transcription of miR-100 in certain types of cancer.

2) $\mathrm{miR}-101: \mathrm{miR}-101$ is downregulated in various cancers, including ovarian cancer, prostate cancer, hepatocellular carcinoma, bladder transitional cell carcinoma, gastric cancer, and non-small cell lung cancer, and is negatively associated with the progression and invasion of malignancies, such as prostate cancer (Gui and Shen, 2012). In human osteosarcoma cells, miR101 directly targets mTOR and decreases its expression, resulting in the suppression of cell proliferation and induction of apoptosis (Lin et al., 2014). Interestingly, p53 promotes the maturation of miR-101 at the post-transcriptional level (Fujiwara et al., 2018). Therefore, p53 may inhibit the mTOR pathway by posttranscriptional activation of miR-101.

3) miR-145: miR-145, a direct target of p53, binds to the $3^{\prime}$ UTR of c-MYC and inhibits its expression, thereby repressing cancer cell growth both in vitro and in vivo (Sachdeva et al., 2009). Moreover, miR-145 suppresses S6K1 expression at the posttranscriptional level to inhibit tumorigenesis and tumor angiogenesis (Xu et al., 2012). Furthermore, p53-mediated transcription of miR-145 may suppress tumor growth by cooperatively inhibiting the oncogenic functions of c-MYC and the mTOR pathway.

4) miR-149: miR-149 plays a dual role, that is controversial, either as a tumor suppressor or as an oncogene in different types of cancer (Wang Y. et al., 2012). miR-149 inhibits the tumorigenesis of hepatocellular carcinoma (HCC) via directly targeting AKT1 to regulate the AKT/mTOR pathway (Zhang Y. et al., 2014). However, miR-149, which is directly upregulated by p53, acts as an oncogenic regulator in melanoma cells by targeting glycogen synthase kinase $3 \alpha$ (GSK3a) to stabilize MCL-1 and inhibit apoptosis (Jin et al., 2011). Thus, it will be intriguing to characterize the unique role of the p53-miR-149-AKT/mTOR axis in different types of tumors.

5) miR-155: miR-155 targets several components of the mTOR pathway, including Rheb, Rictor, and S6K2, by directly binding to their 3'-UTRs (Wang et al., 2013; Wan et al., 2014). By interfering with both mTORC1 and mTORC2 signals, miR-155 suppresses cell proliferation, activates autophagy, and induces G1/S cell cycle arrest. Additionally, it has been reported that under high glucose conditions, p53 directly promotes miR-155 expression as a transcription factor in human renal proximal tubule (HK-2) cells (Wang et al., 2018). However, the role of p53 in regulating the transcription of miR-155 under normal conditions or upon glucose deprivation, and the functions of the p53-miR-155-mTOR pathway in physiological and pathological processes remain largely unknown.

6) miR-199a-3p: miR-199a-3p is upregulated by $p 53$ at the post-transcriptional level (Wang J. et al., 2012). miR-199a-3p directly interacts with the $3^{\prime}$-UTR of mTOR and inhibits the mTOR pathway and restrains endometrial cancer cell proliferation ( $\mathrm{Wu}$ et al., 2013) as well as increases the sensitivity of HCC cells to doxorubicin-induced apoptosis (Fornari et al., 2010). Given that p53 is highly activated in response to DNA damage, due to genotoxic treatments (e.g., doxorubicin), it is probable that the p53-miR-199a-3p-mTOR pathway regulates cancer cell survival during chemotherapy or radiotherapy.

\section{Non-Transcriptional Effects of p53 in Regulating the mTOR Pathway}

In general, the tumor suppressor p53 regulates various cellular processes via trans-activating or trans-repressing downstream gene expression as a transcription factor. Interestingly, in recent decades, several studies have shown that in addition to its activity in the nucleus, p53 exhibits transcription independent functions in the cytoplasm (Comel et al., 2014). The best-characterized 
extranuclear function of p53 is the induction of apoptosis. It has been reported that overexpression of a truncated murine p53 (p53dl214), containing only 214 amino acid residues of the $\mathrm{N}$-terminus and lacking DNA-binding activity, could trigger extensive apoptosis in HeLa cells as well (Haupt et al., 1995). Mechanistically, upon apoptotic induction, p53 translocates from the nucleus to the mitochondrial outer membrane, and interacts with pro-survival Bcl-2 family members (such as Bcl-w and Bcl$\mathrm{X}_{\mathrm{L}}$ ) to release pro-apoptotic Bcl-2 proteins (such as Bax and Bak) to induce apoptosis (Vaseva and Moll, 2009; Czabotar et al., 2014). Moreover, cytosolic p53 regulates autophagy via the mTOR pathway.

Autophagy, a cellular catabolic process that recycles unwanted proteins and damaged organelles in the lysosomes, is regulated by two biologically significant molecules: mTOR and AMPK. mTORC1 inhibits autophagosome formation by phosphorylating ULK1 at Ser757 to suppress the ULK1 complex (Kim et al., 2011), and mTORC2 restrains the transcription of several ATGs via AKT-FoxO3 signaling to inhibit autophagy (Guertin et al., 2006; Zhao et al., 2008). However, AMPK plays a positive role in autophagy induction. On one hand, AMPK can phosphorylate TSC2 and Raptor to inhibit mTOR (Inoki et al., 2003; Gwinn et al., 2008); on the other hand, AMPK can directly phosphorylate ULK1 at Ser317 and Ser777 to activate the ULK1 complex and initiate autophagy (Kim et al., 2011). Notably, the tumor suppressor $\mathrm{p} 53$ has a dual role in the regulation of autophagy. As a transcription factor, p53 transactivates several genes that induce autophagy, including TSC2 (Feng et al., 2007), AMPK $\beta 1$ (Feng et al., 2007), Sestrin1/2 (Budanov and Karin, 2008), and DRAM (Crighton et al., 2006). However, cytosolic p53, either the wild-type or mutant form, represses autophagy (Tasdemir et al., 2008a; Tasdemir et al., 2008b). In fact, various known autophagyinducing stimuli, such as rapamycin treatment or ER stress, cause the cytoplasmic translocation of $\mathrm{p} 53$, which is subsequently degraded via MDM2-mediated ubiquitination (Pluquet et al., 2005; Yorimitsu et al., 2006). Consistently, pharmacological inhibition or depletion of p53 induces autophagy in nematodes, mice, and human cells under normal conditions (Tasdemir et al., 2008b). Moreover, p53 suppresses autophagy through a non-transcriptional effect via cytoplasmic localization, which is supported by the following evidence: 1) expression of both wild-type and ER-targeted p53 inhibited high levels of basal autophagy in HCT116 $p 53^{-/-}$cells; 2) expression of nuclear p53 (disturbed NES by L348A and L350A) failed to inhibit autophagy; and 3) a point mutation (R175H) in $\mathrm{p} 53$ that induces a conformational change, abrogated the autophagy-inhibitory effect of p53 (Tasdemir et al., 2008b). However, the exact molecular mechanism by which cytoplasmic p53 inhibits autophagy remains to be elucidated. It seems that cytoplasmic p53 inhibits autophagy through a mechanism different from its function in apoptosis, since BH3-only proteins (such as Beclin-1) are autophagy inducers, but not suppressors (Maiuri et al., 2007). Current research highlights the involvement of the mTOR pathway in regulating cytoplasmic p53-induced autophagy. In HCT116 $p 53^{-/-}$cells with higher basal levels of autophagy,
S6K, an mTOR substrate, was hypophosphorylated, whereas AMPK and its substrate ACC were hyperphosphorylated. In addition, cytoplasmic, but not nuclear, p53 inhibited AMPK (reflected by reduced phosphorylation of AMPK, ACC, and TSC2) and activated mTOR (reflected by an increased phosphorylation of S6K) to suppress autophagy (Tasdemir et al., 2008b). These results indicate that cytoplasmic p53 can regulate the AMPK-mTOR axis, but the molecular details remain unclear. Since cytoplasmic p53 can regulate cellular processes by modulating protein-protein interactions, it is important to identify novel cytoplasmic p53-binding proteins, which are involved in controlling mTOR activity, to uncover the exact role of cytoplasmic p53 in regulating the mTOR pathway.

\section{Regulation of p53 by the mTOR Pathway}

The coordination of growth signals and stresses is also adjusted by the reverse regulation of $\mathrm{p} 53$ by the mTOR pathway. The role of the mTOR pathway in regulating p53 activity is complex, and is mainly focused on modulating the protein levels of p53 and/or MDM2, a negative regulator of p53. Activating the mTOR signaling by growth factors, such as IGF-1 and hepatocyte growth factor (HGF), induces MDM2 translation in a PI3KAKT dependent manner. On the other hand, inhibition of mTORC1 by rapamycin downregulating MDM2, induces p53dependent apoptosis, and sensitizes cancer cells to chemotherapy (Moumen et al., 2007; Du et al., 2013). Additionally, the treatment of Torin1 (an inhibitor of both mTORC1 and mTORC2) or PF04691502 (a dual PI3K/mTOR inhibitor) increases the expression of 553 protein via inhibition of mTOR signaling (Ekshyyan et al., 2013; Herzog et al., 2013; Garbern et al., 2020). However, in Tsc1 or Tsc2 deletion MEF cells, constitutive mTOR activation promotes the association of p53 mRNA with polysomes to induce its translation (Lee et al., 2007).

In addition to the modulation of p53 activity via changing MDM2 or $\mathrm{p} 53$ protein synthesis, the mTOR signaling regulates p53 activity at post-translational levels. First, in PTEN-depleted cells, mTORC1 and mTORC2 compete with MDM2 to bind p53 and phosphorylate it at Ser15, which is the first step to activate p53, leading to PTEN-loss-induced cellular senescence (PICS) (Jung et al., 2019). However, PTEN activates p53 and sensitizes tumor cells to chemotherapy by retaining MDM2 in the cytoplasm (Mayo et al., 2002). And PTEN also promotes p53 transcription activity by regulating its DNA binding independent of MDM2 (Freeman et al., 2003). Second, upon glucose deprivation, phosphorylation of p53 at Ser15 by AMPK leads to cell cycle arrest (Jones et al., 2005). Furthermore, LKB1, the upstream activator of AMPK, directly or indirectly phosphorylates p53 at Ser15 and Ser392, and activates the transcription of $p 21$ following UV treatment (Zeng and Berger, 2006). Third, AKT promotes p53 degradation by directly phosphorylating MDM2 on Ser166 and/or Ser186, which facilitates the nuclear translocation of MDM2 (Mayo and Donner, 2001; Zhou et al., 2001) and stabilizes it (Feng et al., 2004). Particularly, in vivo studies using $\mathrm{Mdm} 2^{\mathrm{S} 183 \mathrm{~A}}$ mice recently showed that AKT phosphorylation of Mdm2 at Ser183 (the murine equivalent of human Ser186) suppresses p53mediated senescence, facilitates ROS-induced tumorigenesis, 


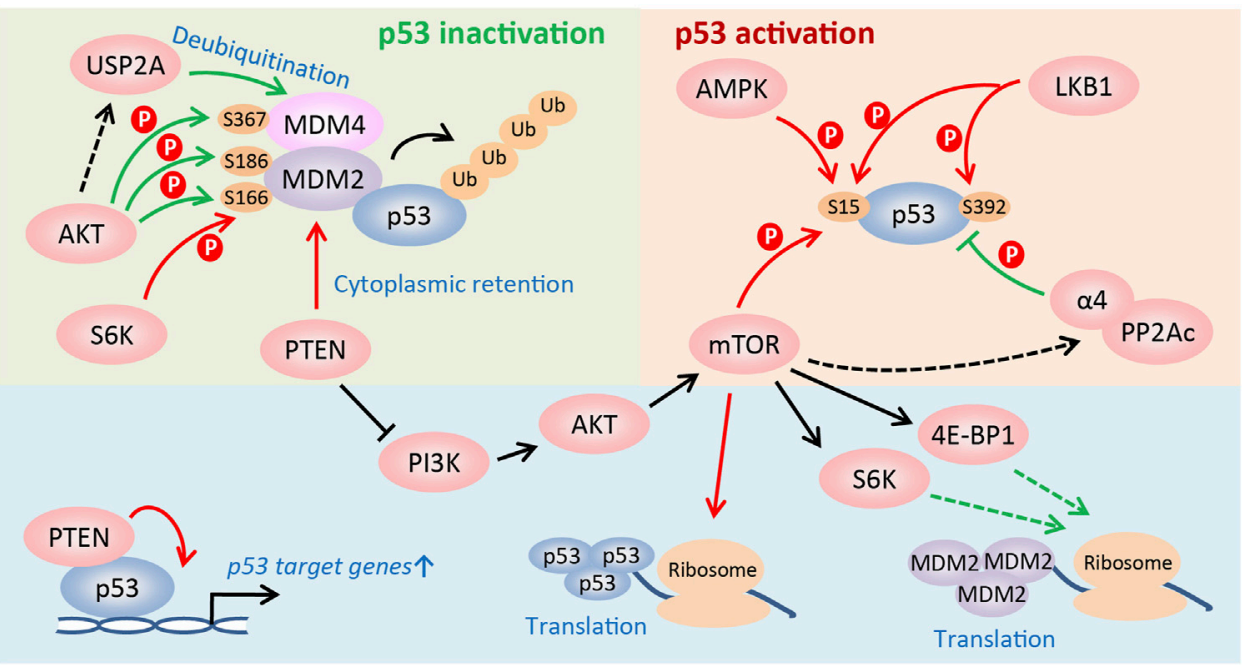

FIGURE 2 |Regulation of p53 activity by the mTOR pathway. The PI3K/AKT/mTOR pathway regulates the activity of p53 at multiple levels, such as translational and post-translational levels, etc. The mTOR pathway is able to either positively or negatively regulate p53 activity in a cell type and stress-dependent manner. See text for details (Red arrow: to promote p53 activity; green arrow: to suppress p53 activity).

and has no effects on DNA damage response induced by radiation (Chibaya et al., 2021). Moreover, AKT also regulates phosphorylation of MDM4, which complexes with MDM2 to degrade p53, at Ser367 to stabilize it and consequently inactivate p53 (Lopez-Pajares et al., 2008; Pellegrino et al., 2014). Additionally, AKT may protect MDM4 from proteolysis by inducing the ubiquitin-specific protease $2 \mathrm{a}$ (USP2A) to deubiquitinate it (Allende-Vega et al., 2010; Calvisi et al., 2011; Pellegrino et al., 2014). Fourth, in addition to phosphorylating MDM2 on Ser166, S6K1 interacts strongly with MDM2 and inhibits MDM2-mediated p53 degradation in response to DNA damage (Lai et al., 2010). Finally, a4, a nonanalytic subunit of protein phosphatase 2A (PP2A), dephosphorylates p53 and suppresses apoptosis by inhibiting expression of p53 target genes, such as NOXA and p21 (Kong et al., 2004). Rapamycin treatment disrupts the association of $a 4$ with PP2Ac, the catalytic subunit of PP2A, to suppress the phosphatase activity of PP2A (Murata et al., 1997; Inui et al., 1998; Kong et al., 2004), indicating that activating mTOR signaling promotes p53 dephosphorylation and represses its activity. Collectively, the mTOR pathway is able to either positively or negatively regulate p53 activity in a cell type- and stress-dependent manner (Figure 2).

\section{CONCLUSIONS AND FUTURE PERSPECTIVES}

In summary, the coordinated regulation of the tumor suppressor p53 and the mTOR pathway is critical for cells and organisms to maintain homeostasis in response to various stimuli. p53 controls the mTOR pathway at multiple levels: 1) p53 directly regulates several signaling mechanisms in the mTOR pathway; 2) miRNAs, downstream of $\mathrm{p} 53$, regulate the mTOR pathway at the post- transcriptional level; 3) cytoplasmic p53 may control the AMPKmTOR axis to inhibit autophagy by protein-protein interaction. In contrast, the mTOR pathway regulates p53 activity mainly by monitoring the interaction between $\mathrm{p} 53$ and its E3 ubiquitin ligase, MDM2. Although some cross talk between p53 and the mTOR pathway has been addressed, many fundamental questions remain unanswered such as: 1) Are the other regulators or components of the mTORC1 complex, the transcriptional targets of p53? 2) How does cytoplasmic p53 activate AMPK and suppress mTOR? 3) What is the precise role of p53 in regulating mTORC2, which has been poorly studied? 4) Does mTOR or its downstream effectors directly phosphorylate other sites of p53 in addition to Ser15 and regulate p53 function under physiological or "stress" conditions? 5) Do the in vitro findings truly indicate those in vivo physiological and pathological conditions (genetically modified mouse models and clinical patient samples)? The answers to these questions will advance our current understanding of the manner in which the cross talk between p53 and mTOR pathways regulates tumorigenesis.

Interestingly, activating p53 and inhibiting mTOR may be an effective strategy for combating coronaviruses (CoVs) such as COVID-19-causing SARS-CoV-2. During viral infection and replication, mTOR is activated and promotes type-I interferon expression in the presence of MyD88, TLR9, and IRF-7. mTOR inhibitors suppress viral infection and replication in the early stages (Ramaiah, 2020). Recent studies have indicated that several mTOR inhibitors, such as rapamycin and metformin, are potential COVID-19 inhibitors (Gordon et al., 2020; Sharma et al., 2020). However, p53 is an anti-viral factor that is degraded by the E3 ubiquitin ligase RCHY1 upon SARS-CoV infection (Ma-Lauer et al., 2016). Since p53 target genes in the mTOR pathway are mainly negative regulators of mTORC1, p53 activators, such as Nutlin-3a, could help in inhibiting SARS$\mathrm{CoV}-2$ replication by suppressing mTOR activity. 


\section{AUTHOR CONTRIBUTIONS}

DC drafted the manuscript. RQ, DL, XX and TL revised the manuscript. YZ conceptualized, revised, and finalized the manuscript.

\section{REFERENCES}

Allende-Vega, N., Sparks, A., Lane, D. P., and Saville, M. K. (2010). MdmX Is a Substrate for the Deubiquitinating Enzyme USP2a. Oncogene 29, 432-441. doi:10.1038/onc. 2009.330

Babashah, S., and Soleimani, M. (2011). The Oncogenic and Tumour Suppressive Roles of microRNAs in Cancer and Apoptosis. Eur. J. Cancer 47, 1127-1137. doi:10.1016/j.ejca.2011.02.008

Barak, Y., Juven, T., Haffner, R., and Oren, M. (1993). mdm2 Expression Is Induced by Wild Type P53 Activity. EMBO J. 12, 461-468. doi:10.1002/j.14602075.1993.tb05678.x

Brugarolas, J., Lei, K., Hurley, R. L., Manning, B. D., Reiling, J. H., Hafen, E., et al. (2004). Regulation of mTOR Function in Response to Hypoxia by REDD1 and the TSC1/TSC2 Tumor Suppressor Complex. Genes Develop. 18, 2893-2904. doi:10.1101/gad.1256804

Budanov, A. V., and Karin, M. (2008). p53 Target Genes Sestrin1 and Sestrin2 Connect Genotoxic Stress and mTOR Signaling. Cell 134, 451-460. doi:10.1016/j.cell.2008.06.028

Budanov, A. V., Shoshani, T., Faerman, A., Zelin, E., Kamer, I., Kalinski, H., et al. (2002). Identification of a Novel Stress-Responsive Gene Hi95 Involved in Regulation of Cell Viability. Oncogene 21, 6017-6031. doi:10.1038/ sj.onc. 1205877

Calvisi, D. F., Wang, C., Ho, C., Ladu, S., Lee, S. A., Mattu, S., et al. (2011). Increased Lipogenesis, Induced by AKT-mTORC1-RPS6 Signaling, Promotes Development of Human Hepatocellular Carcinoma. Gastroenterology 140, 1071-1083. doi:10.1053/j.gastro.2010.12.006

Chao, C. C.-K. (2015). Mechanisms of P53 Degradation. Clinica Chim. Acta 438, 139-147. doi:10.1016/j.cca.2014.08.015

Chibaya, L., Karim, B., Zhang, H., and Jones, S. N. (2021). Mdm2 Phosphorylation by Akt Regulates the P53 Response to Oxidative Stress to Promote Cell Proliferation and Tumorigenesis. Proc. Natl. Acad. Sci. USA 118, e2003193118. doi:10.1073/pnas.2003193118

Co, N. N., Iglesias, D., Celestino, J., Kwan, S. Y., Mok, S. C., Schmandt, R., et al. (2014). Loss of LKB1 in High-Grade Endometrial Carcinoma: LKB1 Is a Novel Transcriptional Target of P53. Cancer 120, 3457-3468. doi:10.1002/cncr.28854

Comel, A., Sorrentino, G., Capaci, V., and Del Sal, G. (2014). The Cytoplasmic Side of P53's Oncosuppressive Activities. FEBS Lett. 588, 2600-2609. doi:10.1016/ j.febslet.2014.04.015

Crighton, D., Wilkinson, S., O'prey, J., Syed, N., Smith, P., Harrison, P. R., et al. (2006). DRAM, a P53-Induced Modulator of Autophagy, Is Critical for Apoptosis. Cell 126, 121-134. doi:10.1016/j.cell.2006.05.034

Cui, D., Dai, X., Gong, L., Chen, X., Wang, L., Xiong, X., et al. (2020a). DEPTOR Is a Direct P53 Target that Suppresses Cell Growth and Chemosensitivity. Cell Death Dis 11, 976. doi:10.1038/s41419-020-03185-3

Cui, D., Xiong, X., Shu, J., Dai, X., Sun, Y., and Zhao, Y. (2020b). FBXW7 Confers Radiation Survival by Targeting P53 for Degradation. Cel Rep. 30, 497-509. doi:10.1016/j.celrep.2019.12.032

Czabotar, P. E., Lessene, G., Strasser, A., and Adams, J. M. (2014). Control of Apoptosis by the BCL-2 Protein Family: Implications for Physiology and Therapy. Nat. Rev. Mol. Cel Biol 15, 49-63. doi:10.1038/nrm3722

Deyoung, M. P., Horak, P., Sofer, A., Sgroi, D., and Ellisen, L. W. (2008). Hypoxia Regulates TSC1/2 mTOR Signaling and Tumor Suppression through REDD1Mediated 1433 Shuttling. Genes Develop. 22, 239-251. doi:10.1101/ gad.1617608

Du, W., Yi, Y., Zhang, H., Bergholz, J., Wu, J., Ying, H., et al. (2013). Rapamycin Inhibits IGF-1-Mediated Up-Regulation of MDM2 and Sensitizes Cancer Cells to Chemotherapy. PLoS One 8, e63179. doi:10.1371/ journal.pone.0063179

\section{FUNDING}

This work was supported by the National Natural Science Foundation of China $(92053117,81972591$, and 81672728 to YZ, 82002924 to DC, 81572708,81974429 , and 8217110231 to XX).

Ekshyyan, O., Anandharaj, A., and Nathan, C.-A. O. (2013). Dual PI3K/mTOR Inhibitors: Does P53 Modulate Response?. Clin. Cancer Res. 19, 3719-3721. doi:10.1158/1078-0432.CCR-13-1291

El-Deiry, W., Tokino, T., Velculescu, V. E., Levy, D. B., Parsons, R., Trent, J. M., et al. (1993). WAF1, a Potential Mediator of P53 Tumor Suppression. Cell 75, 817-825. doi:10.1016/0092-8674(93)90500-p

Ellisen, L. W., Ramsayer, K. D., Johannessen, C. M., Yang, A., Beppu, H., Minda, K., et al. (2002). REDD1, a Developmentally Regulated Transcriptional Target of P63 and P53, Links P63 to Regulation of Reactive Oxygen Species. Mol. Cel 10, 995-1005. doi:10.1016/s1097-2765(02)00706-2

Feng, J., Tamaskovic, R., Yang, Z., Brazil, D. P., Merlo, A., Hess, D., et al. (2004). Stabilization of Mdm2 via Decreased Ubiquitination Is Mediated by Protein Kinase B/Akt-dependent Phosphorylation. J. Biol. Chem. 279, 35510-35517. doi:10.1074/jbc.M404936200

Feng, Z., Hu, W., De Stanchina, E., Teresky, A. K., Jin, S., Lowe, S., et al. (2007). The Regulation of AMPK $\beta 1$, TSC2, and PTEN Expression by P53: Stress, Cell and Tissue Specificity, and the Role of These Gene Products in Modulating the IGF1-AKT-mTOR Pathways. Cancer Res. 67, 3043-3053. doi:10.1158/00085472.CAN-06-4149

Fischer, M. (2017). Census and Evaluation of P53 Target Genes. Oncogene 36, 3943-3956. doi:10.1038/onc.2016.502

Fornari, F., Milazzo, M., Chieco, P., Negrini, M., Calin, G. A., Grazi, G. L., et al. (2010). MiR-199a-3p Regulates mTOR and C-Met to Influence the Doxorubicin Sensitivity of Human Hepatocarcinoma Cells. Cancer Res. 70, 5184-5193. doi:10.1158/0008-5472.CAN-10-0145

Freeman, D. J., Li, A. G., Wei, G., Li, H.-H., Kertesz, N., Lesche, R., et al. (2003). PTEN Tumor Suppressor Regulates P53 Protein Levels and Activity through Phosphatase-dependent and -independent Mechanisms. Cancer Cell 3, 117-130. doi:10.1016/s1535-6108(03)00021-7

Fu, W., and Hall, M. N. (2020). Regulation of mTORC2 Signaling. Genes 11, 1045. doi:10.3390/genes11091045

Fujiwara, Y., Saito, M., Robles, A. I., Nishida, M., Takeshita, F., Watanabe, M., et al. (2018). A Nucleolar Stress-specific P53-miR-101 Molecular Circuit Functions as an Intrinsic Tumor-Suppressor Network. EBioMedicine 33, 33-48. doi:10.1016/j.ebiom.2018.06.031

Galindo-Moreno, M., Giráldez, S., Limón-Mortés, M. C., Belmonte-Fernández, A. Reed, S. I., Sáez, C., et al. (2019). SCF(FBXW7)-mediated Degradation of P53 Promotes Cell Recovery after UV-induced DNA Damage. FASEB j. 33, 11420-11430. doi:10.1096/fj.201900885R

Garbern, J. C., Helman, A., Sereda, R., Sarikhani, M., Ahmed, A., Escalante, G. O., et al. (2020). Inhibition of mTOR Signaling Enhances Maturation of Cardiomyocytes Derived from Human-Induced Pluripotent Stem Cells via P53-Induced Quiescence. Circulation 141, 285-300. doi:10.1161/ CIRCULATIONAHA.119.044205

Ge, Y., Wu, S., Zhang, Z., Li, X., Li, F., Yan, S., et al. (2019). Inhibition of P53 And/ or AKT as a New Therapeutic Approach Specifically Targeting ALT Cancers. Protein Cell 10, 808-824. doi:10.1007/s13238-019-0634-z

Ghose, J., and Bhattacharyya, N. P. (2015). Transcriptional Regulation of microRNA-100, -146a, and -150 Genes by P53 and NFkB p65/RelA in Mouse Striatal STHdhQ7/HdhQ7cells and Human Cervical Carcinoma HeLa Cells. RNA Biol. 12, 457-477. doi:10.1080/15476286.2015.1014288

Gordon, D. E., Jang, G. M., Bouhaddou, M., Xu, J., Obernier, K., White, K. M., et al. (2020). A SARS-CoV-2 Protein Interaction Map Reveals Targets for Drug Repurposing. Nature 583, 459-468. doi:10.1038/s41586-020-2286-9

Guertin, D. A., Stevens, D. M., Thoreen, C. C., Burds, A. A., Kalaany, N. Y., Moffat, J., et al. (2006). Ablation in Mice of the mTORC Components Raptor, Rictor, or mLST8 Reveals that mTORC2 Is Required for Signaling to Akt-FOXO and PKCa, but Not S6K1. Develop. Cel 11, 859-871. doi:10.1016/ j.devcel.2006.10.007 
Gui, T., and Shen, K. (2012). miRNA-101: a Potential Target for Tumor Therapy. Cancer Epidemiol. 36, 537-540. doi:10.1016/j.canep.2012.05.004

Gwinn, D. M., Shackelford, D. B., Egan, D. F., Mihaylova, M. M., Mery, A., Vasquez, D. S., et al. (2008). AMPK Phosphorylation of Raptor Mediates a Metabolic Checkpoint. Mol. Cel 30, 214-226. doi:10.1016/j.molcel.2008.03.003

Haar, E. V., Lee, S.-i., Bandhakavi, S., Griffin, T. J., and Kim, D.-H. (2007). Insulin Signalling to mTOR Mediated by the Akt/PKB Substrate PRAS40. Nat. Cel Biol 9, 316-323. doi:10.1038/ncb1547

Hafner, A., Bulyk, M. L., Jambhekar, A., and Lahav, G. (2019). The Multiple Mechanisms that Regulate P53 Activity and Cell Fate. Nat. Rev. Mol. Cel Biol 20, 199-210. doi:10.1038/s41580-019-0110-x

Hainaut, P., and Hollstein, M. (2000). p53 and Human Cancer: the First Ten Thousand Mutations. Adv. Cancer Res. 77, 81-137. doi:10.1016/s0065-230x(08) 60785-x

Hanahan, D., and Weinberg, R. A. (2011). Hallmarks of Cancer: the Next Generation. Cell 144, 646-674. doi:10.1016/j.cell.2011.02.013

Harrington, L. S., Findlay, G. M., Gray, A., Tolkacheva, T., Wigfield, S., Rebholz, H., et al. (2004). The TSC1-2 Tumor Suppressor Controls Insulin-Pi3k Signaling via Regulation of IRS Proteins. J. Cel Biol 166, 213-223. doi:10.1083/ jcb.200403069

Haupt, Y., Rowan, S., Shaulian, E., Vousden, K. H., and Oren, M. (1995). Induction of Apoptosis in HeLa Cells by Trans-activation-deficient P53. Genes Develop. 9, 2170-2183. doi:10.1101/gad.9.17.2170

He, H., and Sun, Y. (2007). Ribosomal Protein S27L Is a Direct P53 Target that Regulates Apoptosis. Oncogene 26, 2707-2716. doi:10.1038/sj.onc.1210073

Hermeking, H. (2007). p53 Enters the microRNA World. Cancer Cell 12, 414-418. doi:10.1016/j.ccr.2007.10.028

Hermeking, H. (2012). MicroRNAs in the P53 Network: Micromanagement of Tumour Suppression. Nat. Rev. Cancer 12, 613-626. doi:10.1038/nrc3318

Herzog, A., Bian, Y., Vander Broek, R., Hall, B., Coupar, J., Cheng, H., et al. (2013). PI3K/mTOR Inhibitor PF-04691502 Antitumor Activity Is Enhanced with Induction of Wild-type TP53 in Human Xenograft and Murine Knockout Models of Head and Neck Cancer. Clin. Cancer Res. 19, 3808-3819. doi:10.1158/1078-0432.CCR-12-2716

Hock, A. K., and Vousden, K. H. (2014). The Role of Ubiquitin Modification in the Regulation of P53. Biochim. Biophys. Acta (Bba) - Mol. Cel Res. 1843, 137-149. doi:10.1016/j.bbamcr.2013.05.022

Hsu, P. P., Kang, S. A., Rameseder, J., Zhang, Y., Ottina, K. A., Lim, D., et al. (2011). The mTOR-Regulated Phosphoproteome Reveals a Mechanism of mTORC1Mediated Inhibition of Growth Factor Signaling. Science 332, 1317-1322. doi:10.1126/science.1199498

Inoki, K., Li, Y., Zhu, T., Wu, J., and Guan, K.-L. (2002). TSC2 Is Phosphorylated and Inhibited by Akt and Suppresses mTOR Signalling. Nat. Cel Biol 4, 648-657. doi:10.1038/ncb839

Inoki, K., Zhu, T., and Guan, K.-L. (2003). TSC2 Mediates Cellular Energy Response to Control Cell Growth and Survival. Cell 115, 577-590. doi:10.1016/s0092-8674(03)00929-2

Inui, S., Sanjo, H., Maeda, K., Yamamoto, H., Miyamoto, E., and Sakaguchi, N. (1998). Ig Receptor Binding Protein 1 (a4) Is Associated with a RapamycinSensitive Signal Transduction in Lymphocytes through Direct Binding to the Catalytic Subunit of Protein Phosphatase 2A. Blood 92, 539-546. doi:10.1182/ blood.v92.2.539

Jin, L., Hu, W. L., Jiang, C. C., Wang, J. X., Han, C. C., Chu, P., et al. (2011). MicroRNA-149*, a P53-Responsive microRNA, Functions as an Oncogenic Regulator in Human Melanoma. Proc. Natl. Acad. Sci. 108, 15840-15845. doi:10.1073/pnas.1019312108

Jones, R. G., Plas, D. R., Kubek, S., Buzzai, M., Mu, J., Xu, Y., et al. (2005). AMPactivated Protein Kinase Induces a P53-dependent Metabolic Checkpoint. Mol. Cel 18, 283-293. doi:10.1016/j.molcel.2005.03.027

Jung, S. H., Hwang, H. J., Kang, D., Park, H. A., Lee, H. C., Jeong, D., et al. (2019). mTOR Kinase Leads to PTEN-Loss-Induced Cellular Senescence by Phosphorylating P53. Oncogene 38, 1639-1650. doi:10.1038/s41388-018-0521-8

Kim, J., Kundu, M., Viollet, B., and Guan, K.-L. (2011). AMPK and mTOR Regulate Autophagy through Direct Phosphorylation of Ulk1. Nat. Cel Biol 13, 132-141. doi:10.1038/ncb2152

Kong, M., Fox, C. J., Mu, J., Solt, L., Xu, A., Cinalli, R. M., et al. (2004). The PP2AAssociated Protein a4 Is an Essential Inhibitor of Apoptosis. Science 306, 695-698. doi:10.1126/science.1100537
Kruse, J.-P., and Gu, W. (2009). Modes of P53 Regulation. Cell 137, 609-622. doi:10.1016/j.cell.2009.04.050

Lai, K. P., Leong, W. F., Chau, J. F. L., Jia, D., Zeng, L., Liu, H., et al. (2010). S6K1 Is a Multifaceted Regulator of Mdm2 that Connects Nutrient Status and DNA Damage Response. EMBO J. 29, 2994-3006. doi:10.1038/emboj.2010.166

Lee, C.-H., Inoki, K., Karbowniczek, M., Petroulakis, E., Sonenberg, N., Henske, E. P., et al. (2007). Constitutive mTOR Activation in TSC Mutants Sensitizes Cells to Energy Starvation and Genomic Damage via P53. EMBO J. 26, 4812-4823. doi:10.1038/sj.emboj.7601900

Levine, A. J. (1997). p53, the Cellular Gatekeeper for Growth and Division. Cell 88, 323-331. doi:10.1016/s0092-8674(00)81871-1

Lewis, B. P., Burge, C. B., and Bartel, D. P. (2005). Conserved Seed Pairing, Often Flanked by Adenosines, Indicates that Thousands of Human Genes Are microRNA Targets. Cell 120, 15-20. doi:10.1016/j.cell.2004.12.035

Li, J., Tan, J., Zhuang, L., Banerjee, B., Yang, X., Chau, J. F. L., et al. (2007). Ribosomal Protein S27-like, a P53-Inducible Modulator of Cell Fate in Response to Genotoxic Stress. Cancer Res. 67, 11317-11326. doi:10.1158/ 0008-5472.CAN-07-1088

Liao, H., Xiao, Y., Hu, Y., Xiao, Y., Yin, Z., Liu, L., et al. (2016). Methylationinduced Silencing of miR-34a Enhances Chemoresistance by Directly Upregulating ATG4B-Induced Autophagy through AMPK/mTOR Pathway in Prostate Cancer. Oncol. Rep. 35, 64-72. doi:10.3892/or.2015.4331

Lin, S., Shao, N.-n., Fan, L., Ma, X.-c., Pu, F.-f., and Shao, Z.-w. (2014). Effect of microRNA-101 on Proliferation and Apoptosis of Human Osteosarcoma Cells by Targeting mTOR. J. Huazhong Univ. Sci. Technol. [Med. Sci. 34, 889-895. doi:10.1007/s11596-014-1369-y

Liu, J., Zhang, C., Zhao, Y., and Feng, Z. (2017). MicroRNA Control of P53. J. Cel. Biochem. 118, 7-14. doi:10.1002/jcb.25609

Long, X., Ortiz-Vega, S., Lin, Y., and Avruch, J. (2005). Rheb Binding to Mammalian Target of Rapamycin (mTOR) Is Regulated by Amino Acid Sufficiency. J. Biol. Chem. 280, 23433-23436. doi:10.1074/jbc.C500169200

Lopez-Pajares, V., Kim, M. M., and Yuan, Z.-M. (2008). Phosphorylation of MDMX Mediated by Akt Leads to Stabilization and Induces 14-3-3 Binding. J. Biol. Chem. 283, 13707-13713. doi:10.1074/jbc.M710030200

Lovejoy, C. A., and Cortez, D. (2009). Common Mechanisms of PIKK Regulation. DNA Repair 8, 1004-1008. doi:10.1016/j.dnarep.2009.04.006

Ma, L., Chen, Z., Erdjument-Bromage, H., Tempst, P., and Pandolfi, P. P. (2005). Phosphorylation and Functional Inactivation of TSC2 by Erk. Cell 121, 179-193. doi:10.1016/j.cell.2005.02.031

Ma-Lauer, Y., Carbajo-Lozoya, J., Hein, M. Y., Müller, M. A., Deng, W., Lei, J., et al. (2016). p53 Down-Regulates SARS Coronavirus Replication and Is Targeted by the SARS-Unique Domain and PLprovia E3 Ubiquitin Ligase RCHY1. Proc. Natl. Acad. Sci. USA 113, E5192-E5201. doi:10.1073/pnas.1603435113

Macfarlane, L.-A., and R. Murphy, P. (2010). MicroRNA: Biogenesis, Function and Role in Cancer. $C g$ 11, 537-561. doi:10.2174/138920210793175895

Maiuri, M. C., Le Toumelin, G., Criollo, A., Rain, J.-C., Gautier, F., Juin, P., et al. (2007). Functional and Physical Interaction between Bcl-XL and a BH3-like Domain in Beclin-1. EMBO J. 26, 2527-2539. doi:10.1038/ si.emboj.7601689

Manning, B. D., Tee, A. R., Logsdon, M. N., Blenis, J., and Cantley, L. C. (2002). Identification of the Tuberous Sclerosis Complex-2 Tumor Suppressor Gene Product Tuberin as a Target of the Phosphoinositide 3-kinase/akt Pathway. Mol. Cel 10, 151-162. doi:10.1016/s1097-2765(02)00568-3

Mayo, L. D., Dixon, J. E., Durden, D. L., Tonks, N. K., and Donner, D. B. (2002). PTEN Protects P53 from Mdm2 and Sensitizes Cancer Cells to Chemotherapy. J. Biol. Chem. 277, 5484-5489. doi:10.1074/jbc.M108302200

Mayo, L. D., and Donner, D. B. (2001). A Phosphatidylinositol 3-kinase/Akt Pathway Promotes Translocation of Mdm2 from the Cytoplasm to the Nucleus. Proc. Natl. Acad. Sci. 98, 11598-11603. doi:10.1073/pnas.181181198

Moumen, A., Patane', S., Porras, A., Dono, R., and Maina, F. (2007). Met Acts on Mdm2 via mTOR to Signal Cell Survival during Development. Development 134, 1443-1451. doi:10.1242/dev.02820

Murata, K., Wu, J., and Brautigan, D. L. (1997). B Cell Receptor-Associated Protein 4 Displays Rapamycin-Sensitive Binding Directly to the Catalytic Subunit of Protein Phosphatase 2A. Proc. Natl. Acad. Sci. 94, 10624-10629. doi:10.1073/ pnas.94.20.10624

Nakano, K., and Vousden, K. H. (2001). PUMA, a Novel Proapoptotic Gene, Is Induced by P53. Mol. Cel 7, 683-694. doi:10.1016/s1097-2765(01)00214-3 
Oda, E., Ohki, R., Murasawa, H., Nemoto, J., Shibue, T., Yamashita, T., et al. (2000). Noxa, a BH3-Only Member of the Bcl-2 Family and Candidate Mediator of P53-Induced Apoptosis. Science 288, 1053-1058. doi:10.1126/ science.288.5468.1053

Ozaki, T., and Nakagawara, A. (2011). Role of P53 in Cell Death and Human Cancers. Cancers 3, 994-1013. doi:10.3390/cancers3010994

Pellegrino, R., Calvisi, D. F., Neumann, O., Kolluru, V., Wesely, J., Chen, X., et al. (2014). EEF1A2 Inactivates P53 by Way of PI3K/AKT/mTOR-dependent Stabilization of MDM4 in Hepatocellular Carcinoma. Hepatology 59, 1886-1899. doi:10.1002/hep.26954

Peterson, T. R., Laplante, M., Thoreen, C. C., Sancak, Y., Kang, S. A., Kuehl, W. M., et al. (2009). DEPTOR Is an mTOR Inhibitor Frequently Overexpressed in Multiple Myeloma Cells and Required for Their Survival. Cell 137, 873-886. doi:10.1016/j.cell.2009.03.046

Pluquet, O., Qu, L.-K., Baltzis, D., and Koromilas, A. E. (2005). Endoplasmic Reticulum Stress Accelerates P53 Degradation by the Cooperative Actions of Hdm2 and Glycogen Synthase Kinase 3 $\beta$. Mol. Cel Biol 25, 9392-9405. doi:10.1128/MCB.25.21.9392-9405.2005

Potter, C. J., Pedraza, L. G., and Xu, T. (2002). Akt Regulates Growth by Directly Phosphorylating Tsc2. Nat. Cel Biol 4, 658-665. doi:10.1038/ncb840

Ramaiah, M. J. (2020). mTOR Inhibition and P53 Activation, microRNAs: The Possible Therapy against Pandemic COVID-19. Gene Rep. 20, 100765. doi:10.1016/j.genrep.2020.100765

Roux, P. P., Ballif, B. A., Anjum, R., Gygi, S. P., and Blenis, J. (2004). Tumorpromoting Phorbol Esters and Activated Ras Inactivate the Tuberous Sclerosis Tumor Suppressor Complex via P90 Ribosomal S6 Kinase. Proc. Natl. Acad. Sci. 101, 13489-13494. doi:10.1073/pnas.0405659101

Sabatini, D. M., Erdjument-Bromage, H., Lui, M., Tempst, P., and Snyder, S. H. (1994). RAFT1: a Mammalian Protein that Binds to FKBP12 in a Rapamycindependent Fashion and Is Homologous to Yeast TORs. Cell 78, 35-43. doi:10.1016/0092-8674(94)90570-3

Sachdeva, M., Zhu, S., Wu, F., Wu, H., Walia, V., Kumar, S., et al. (2009). p53 Represses C-Myc through Induction of the Tumor Suppressor miR-145. Proc. Natl. Acad. Sci. 106, 3207-3212. doi:10.1073/pnas.0808042106

Sancak, Y., Bar-Peled, L., Zoncu, R., Markhard, A. L., Nada, S., and Sabatini, D. M. (2010). Ragulator-Rag Complex Targets mTORC1 to the Lysosomal Surface and Is Necessary for its Activation by Amino Acids. Cell 141, 290-303. doi:10.1016/j.cell.2010.02.024

Sancak, Y., Peterson, T. R., Shaul, Y. D., Lindquist, R. A., Thoreen, C. C., Bar-Peled, L., et al. (2008). The Rag GTPases Bind Raptor and Mediate Amino Acid Signaling to mTORC1. Science 320, 1496-1501. doi:10.1126/science.1157535

Sancak, Y., Thoreen, C. C., Peterson, T. R., Lindquist, R. A., Kang, S. A., Spooner, E., et al. (2007). PRAS40 Is an Insulin-Regulated Inhibitor of the mTORC1 Protein Kinase. Mol. Cel 25, 903-915. doi:10.1016/ j.molcel.2007.03.003

Saxton, R. A., and Sabatini, D. M. (2017). mTOR Signaling in Growth, Metabolism, and Disease. Cell 168, 960-976. doi:10.1016/j.cell.2017.02.004

Scaiola, A., Mangia, F., Imseng, S., Boehringer, D., Berneiser, K., Shimobayashi, M., et al. (2020). The 3.2- $\AA$ Resolution Structure of Human mTORC2. Sci. Adv. 6, eabc1251. doi:10.1126/sciadv.abc1251

Sengupta, S., Peterson, T. R., and Sabatini, D. M. (2010). Regulation of the mTOR Complex 1 Pathway by Nutrients, Growth Factors, and Stress. Mol. Cel 40, 310-322. doi:10.1016/j.molcel.2010.09.026

Shah, O. J., Wang, Z., and Hunter, T. (2004). Inappropriate Activation of the TSC/ Rheb/mTOR/S6K Cassette Induces IRS1/2 Depletion, Insulin Resistance, and Cell Survival Deficiencies. Curr. Biol. 14, 1650-1656. doi:10.1016/j.cub.2004.08.026

Sharma, S., Chatterjee, A., Kumar, P., Lal, S., and Kondabagil, K. (2020). Upregulation of miR-101 during Influenza A Virus Infection Abrogates Viral Life Cycle by Targeting mTOR Pathway. Viruses 12, 444. doi:10.3390/v12040444

Shaw, R. J., Bardeesy, N., Manning, B. D., Lopez, L., Kosmatka, M., Depinho, R. A., et al. (2004). The LKB1 Tumor Suppressor Negatively Regulates mTOR Signaling. Cancer Cell 6, 91-99. doi:10.1016/j.ccr.2004.06.007

Stambolic, V., Macpherson, D., Sas, D., Lin, Y., Snow, B., Jang, Y., et al. (2001). Regulation of PTEN Transcription by P53. Mol. Cel 8, 317-325. doi:10.1016/ s1097-2765(01)00323-9

Sun, J., Chen, Z., Tan, X., Zhou, F., Tan, F., Gao, Y., et al. (2013). MicroRNA-99a/ 100 Promotes Apoptosis by Targeting mTOR in Human Esophageal Squamous Cell Carcinoma. Med. Oncol. 30, 411. doi:10.1007/s12032-012-0411-9
Suzuki, H. I., Yamagata, K., Sugimoto, K., Iwamoto, T., Kato, S., and Miyazono, K. (2009). Modulation of microRNA Processing by P53. Nature 460, 529-533. doi:10.1038/nature08199

Tasdemir, E., Maiuri, M. C., Galluzzi, L., Vitale, I., Djavaheri-Mergny, M., D'amelio, M., et al. (2008b). Regulation of Autophagy by Cytoplasmic P53. Nat. Cel Biol 10, 676-687. doi:10.1038/ncb1730

Tasdemir, E., Maiuri, M. C., Morselli, E., Criollo, A., D’amelio, M., DjavaheriMergny, M., et al. (2008a). A Dual Role of P53 in the Control of Autophagy. Autophagy 4, 810-814. doi:10.4161/auto.6486

Tripathi, V., Kaur, E., Kharat, S. S., Hussain, M., Damodaran, A. P., Kulshrestha, S., et al. (2019). Abrogation of FBW7a-dependent P53 Degradation Enhances P53's Function as a Tumor Suppressor. J. Biol. Chem. 294, 13224-13232. doi:10.1074/jbc.AC119.008483

Tzatsos, A. (2009). Raptor Binds the SAIN (Shc and IRS-1 NPXY Binding) Domain of Insulin Receptor Substrate-1 (IRS-1) and Regulates the Phosphorylation of IRS-1 at Ser-636/639 by mTOR. J. Biol. Chem. 284, 22525-22534. doi:10.1074/ jbc.M109.027748

Um, S. H., Frigerio, F., Watanabe, M., Picard, F., Joaquin, M., Sticker, M., et al. (2004). Absence of S6K1 Protects Against Age- and Diet-Induced Obesity While Enhancing Insulin Sensitivity. Nature 101, 200-205. doi:10.1038/ nature 02866

Vaseva, A. V., and Moll, U. M. (2009). The Mitochondrial P53 Pathway. Biochim. Biophys. Acta (Bba) - Bioenerg. 1787, 414-420. doi:10.1016/ j.bbabio.2008.10.005

Vega-Rubin-De-Celis, S., Abdallah, Z., Kinch, L., Grishin, N. V., Brugarolas, J., and Zhang, X. (2010). Structural Analysis and Functional Implications of the Negative mTORC1 Regulator REDD1,. Biochemistry 49, 2491-2501. doi:10.1021/bi902135e

Velasco-Miguel, S., Buckbinder, L., Jean, P., Gelbert, L., Talbott, R., Laidlaw, J., et al. (1999). PA26, a Novel Target of the P53 Tumor Suppressor and Member of the GADD Family of DNA Damage and Growth Arrest Inducible Genes. Oncogene 18, 127-137. doi:10.1038/sj.onc.1202274

Vousden, K. H., and Prives, C. (2009). Blinded by the Light: The Growing Complexity of P53. Cell 137, 413-431. doi:10.1016/j.cell.2009.04.037

Wan, G., Xie, W., Liu, Z., Xu, W., Lao, Y., Huang, N., et al. (2014). Hypoxiainduced MIR155 Is a Potent Autophagy Inducer by Targeting Multiple Players in the MTOR Pathway. Autophagy 10, 70-79. doi:10.4161/auto.26534

Wang, J., He, Q., Han, C., Gu, H., Jin, L., Li, Q., et al. (2012a). p53-facilitated miR199a-3p Regulates Somatic Cell Reprogramming. Stem Cells 30, 1405-1413. doi:10.1002/stem.1121

Wang, J., Yang, K., Zhou, L., MinhaoWuWu, Y., Wu, Y., Zhu, M., et al. (2013). MicroRNA-155 Promotes Autophagy to Eliminate Intracellular Mycobacteria by Targeting Rheb. Plos Pathog. 9, e1003697. doi:10.1371/ journal.ppat.1003697

Wang, Y., Zheng, X., Zhang, Z., Zhou, J., Zhao, G., Yang, J., et al. (2012b). MicroRNA-149 Inhibits Proliferation and Cell Cycle Progression through the Targeting of ZBTB2 in Human Gastric Cancer. PLoS One 7, e41693. doi:10.1371/journal.pone.0041693

Wang, Y., Zheng, Z.-j., Jia, Y.-j., Yang, Y.-l., and Xue, Y.-m. (2018). Role of p53/ miR-155-5p/sirtl Loop in Renal Tubular Injury of Diabetic Kidney Disease. J. Transl Med. 16, 146. doi:10.1186/s12967-018-1486-7

Wang, Z., Malone, M. H., Thomenius, M. J., Zhong, F., Xu, F., and Distelhorst, C. W. (2003). Dexamethasone-induced Gene 2 (Dig2) Is a Novel Pro-survival Stress Gene Induced Rapidly by Diverse Apoptotic Signals. J. Biol. Chem. 278, 27053-27058. doi:10.1074/jbc.M303723200

Wu, D., Huang, H.-j., He, C.-n., and Wang, K.-y. (2013). MicroRNA-199a-3p Regulates Endometrial Cancer Cell Proliferation by Targeting Mammalian Target of Rapamycin (mTOR). Int. J. Gynecol. Cancer 23, 1191-1197. doi:10.1097/IGC.0b013e31829ea779

Xi, Y., Shalgi, R., Fodstad, O., Pilpel, Y., and Ju, J. (2006). Differentially Regulated Micro-RNAs and Actively Translated Messenger RNA Transcripts by Tumor Suppressor P53 in colon Cancer. Clin. Cancer Res. 12, 2014-2024. doi:10.1158/ 1078-0432.CCR-05-1853

Xie, B., Nagalingam, A., Kuppusamy, P., Muniraj, N., Langford, P., Győrffy, B., et al. (2017). Benzyl Isothiocyanate Potentiates P53 Signaling and Antitumor Effects against Breast Cancer through Activation of P53-LKB1 and P73-LKB1 Axes. Sci. Rep. 7, 40070. doi:10.1038/srep40070

Xu, C., Zeng, Q., Xu, W., Jiao, L., Chen, Y., Zhang, Z., et al. (2013). miRNA100 Inhibits Human Bladder Urothelial Carcinogenesis by Directly 
Targeting mTOR. Mol. Cancer Ther. 12, 207-219. doi:10.1158/15357163.MCT-12-0273

Xu, Q., Liu, L.-Z., Qian, X., Chen, Q., Jiang, Y., Li, D., et al. (2012). MiR-145 Directly Targets p70S6K1 in Cancer Cells to Inhibit Tumor Growth and Angiogenesis. Nucleic Acids Res. 40, 761-774. doi:10.1093/nar/gkr730

Yorimitsu, T., Nair, U., Yang, Z., and Klionsky, D. J. (2006). Endoplasmic Reticulum Stress Triggers Autophagy. J. Biol. Chem. 281, 30299-30304. doi:10.1074/jbc.M607007200

Yu, Y., Yoon, S.-O., Poulogiannis, G., Yang, Q., Ma, X. M., Villén, J., et al. (2011). Phosphoproteomic Analysis Identifies Grb10 as an mTORC1 Substrate that Negatively Regulates Insulin Signaling. Science 332, 1322-1326. doi:10.1126/science.1199484

Zeng, P.-Y., and Berger, S. L. (2006). LKB1 Is Recruited to the p21/WAF1 Promoter by P53 to Mediate Transcriptional Activation. Cancer Res. 66, 10701-10708. doi:10.1158/0008-5472.CAN-06-0999

Zhang, N., Fu, H., Song, L., Ding, Y., Wang, X., Zhao, C., et al. (2014a). MicroRNA100 Promotes Migration and Invasion through Mammalian Target of Rapamycin in Esophageal Squamous Cell Carcinoma. Oncol. Rep. 32, 1409-1418. doi:10.3892/or.2014.3389

Zhang, Y., Guo, X., Xiong, L., Yu, L., Li, Z., Guo, Q., et al. (2014b). Comprehensive Analysis of microRNA-Regulated Protein Interaction Network Reveals the Tumor Suppressive Role of microRNA-149 in Human Hepatocellular Carcinoma via Targeting AKT-mTOR Pathway. Mol. Cancer 13, 253. doi:10.1186/1476-4598-13-253

Zhang, Y., Huang, B., Wang, H.-Y., Chang, A., and Zheng, X. F. S. (2017). Emerging Role of MicroRNAs in mTOR Signaling. Cell. Mol. Life Sci. 74, 2613-2625. doi:10.1007/s00018-017-2485-1

Zhao, J., Brault, J. J., Schild, A., and Goldberg, A. L. (2008). Coordinate Activation of Autophagy and the Proteasome Pathway by FoxO Transcription Factor. Autophagy 4, 378-380. doi:10.4161/auto.5633
Zhao, Y., and Sun, Y. (2012). Targeting the mTOR-DEPTOR Pathway by CRL E3 Ubiquitin Ligases: Therapeutic Application. Neoplasia 14, 360-367. doi:10.1593/neo.12532

Zhao, Y., Xiong, X., and Sun, Y. (2011). DEPTOR, an mTOR Inhibitor, Is a Physiological Substrate of SCF $\beta \operatorname{TrCP}$ E3 Ubiquitin Ligase and Regulates Survival and Autophagy. Mol. Cel 44, 304-316. doi:10.1016/ j.molcel.2011.08.029

Zhou, B. P., Liao, Y., Xia, W., Zou, Y., Spohn, B., and Hung, M.-C. (2001). HER-2/ neu Induces P53 Ubiquitination via Akt-Mediated MDM2 Phosphorylation. Nat. Cel Biol 3, 973-982. doi:10.1038/ncb1101-973

Conflict of Interest: The authors declare that the research was conducted in the absence of any commercial or financial relationships that could be construed as a potential conflict of interest.

Publisher's Note: All claims expressed in this article are solely those of the authors and do not necessarily represent those of their affiliated organizations, or those of the publisher, the editors and the reviewers. Any product that may be evaluated in this article, or claim that may be made by its manufacturer, is not guaranteed or endorsed by the publisher.

Copyright $\odot 2021$ Cui, Qu, Liu, Xiong, Liang and Zhao. This is an open-access article distributed under the terms of the Creative Commons Attribution License (CC BY). The use, distribution or reproduction in other forums is permitted, provided the original author(s) and the copyright owner(s) are credited and that the original publication in this journal is cited, in accordance with accepted academic practice. No use, distribution or reproduction is permitted which does not comply with these terms. 